\title{
PENGARUH PROFITABILITAS, SOLVABILITAS, DAN UKURAN PERUSAHAAN TERHADAP \\ PENGUNGKAPAN SUSTAINABILITY REPORT PADA PERUSAHAAN PERBANKAN YANG TERDAFTAR DI BURSA EFEK INDONESIA DAN BURSA EFEK MALAYSIA \\ PERIODE 2013-2017
}

\author{
Kelvin Setiawan $^{1)}$, Mukhzarudfa ${ }^{2)}$, Achmad Hizazi ${ }^{3)}$ \\ ${ }^{1)}$ Alumni Magister Ilmu Akuntansi Pascasarjana Universitas Jambi Tahun 2019, \\ ${ }^{2 \& 3)}$ Dosen Pembimbing
}

\begin{abstract}
This study aims to examine the effect of profitability, solvency, and firm size on sustainability report disclosures in IDX and Malaysia Stock Exchange banking listed companies for the period 2013-2017. Sampling conducted based on purposive sampling. Total observations that concern in this study were 180 observations. Data were analyzed by multiple linear regression analysis. The empirical results show that the sustainability report disclosures is influenced simultaneously by profitability, solvency, and firm size. Partially, profitability does not affect sustainability report disclosures. Solvability has a negative effect on sustainability report disclosures. Firm size has a positive effect on sustainability report disclosures.
\end{abstract}

Keyword : profitability, solvency, firm size, sustainability report disclosures

\begin{abstract}
ABSTRAK
Penelitian ini bertujuan menguji pengaruh profitabilitas, solvabilitas, dan ukuran perusahaan terhadap pengungkapan sustainability report pada perusahaan perbankan yang terdaftar di BEI dan Bursa Efek Malaysia periode 2013-2017. Penarikan sampel dilakukan berdasarkan purposive sampling. Jumlah observasi yang menjadi perhatian dalam penelitian ini adalah 180 observasi. Data dianalisis dengan analisis regresi linier berganda. Hasil pengujian empiris menunjukkan pengungkapan sustainability report dipengaruhi secara simultan oleh profitabilitas, solvabilitas, dan ukuran perusahaan. Secara parsial, profitabilitas tidak mempengaruhi pengungkapan sustainability report. Solvabilitas berpengaruh negatif terhadap pengungkapan sustainability report. Ukuran perusahaan berpengaruh positif terhadap pengungkapan sustainability report.
\end{abstract}

Kata Kunci: profitabilitas, solvabilitas, ukuran perusahaan, pengungkapan sustainability report. 


\section{PENDAHULUAN}

\subsection{Latar Belakang}

Organisasi khususnya perusahaan saat ini diwajibkan untuk berperan dalam pembangunan berkelanjutan. Salah satu usaha untuk menuju pembangunan berkelanjutan yang transparan dan dapat diukur adalah melalui sustainability reporting disclosure (Simbolon dan Sueb, 2016). Sustainability reporting merupakan alat bagi perusahaan untuk menginformasikan kinerja lingkungan, sosial, dan ekonominya kepada seluruh pemangku kepentingan (stakeholders) (Tarigan dan Semuel, 2014). Perbedaan kepentingan para stakeholder tentunya berpengaruh terhadap operasional perusahaan serta kebijakan pengungkapan informasi yang diberikan oleh perusahaan (Wardani, 2012). Sebagai akibatnya, perusahaan harus bersikap seperti yang diharapkan dari masyarakat demi mempertahankan bisnisnya (O’Donovan, 2002 dalam Ching et al, 2014).

Perusahaan di Indonesia diharuskan untuk berperan aktif dalam melakukan kegiatan CSR (Anggraeni dan Djakman, 2018). Hal tersebut tercermin dari berbagai regulasi yang mengatur kegiatan CSR (UU No. 23 tahun 1997; UU No. 40 tahun 2007; UU No. 32 tahun 2009; PP No. 47 tahun 2012; Peraturan Otoritas Jasa Keuangan No. 51/POJK.03/2017). Namun, pengungkapan CSR dan juga laporan keberlanjutan (sustainability reporting) yang dilakukan perusahaan di Indonesia menurut OJK masih bersifat sukarela. Hal ini terbukti dari data OJK tahun 2016 yang menunjukkan bahwa perusahaan terdaftar di BEI yang telah menerbitkan sustainability report hanyalah sebanyak 49 perusahaan, atau hampir $9 \%$ dari perusahaan yang terdaftar di BEI. Sedangkan 91\% sisanya tidak menerbitkan sustainability report. Diantara 49 perusahaan yang menerbitkan sustainability report, ada 12 perusahaan perbankan yang menerbitkan sustainability report.

Survei mengenai pengungkapan sustainability report di Malaysia salah satunya dilakukan oleh KPMG (Blasco dan King, 2017). Hasil suveinya memperlihatkan bahwa corporate responsibility yang diungkapkan di negara Malaysia termasuk dalam kategori negara dengan persentase pengungkapan corporate responsibility lebih dari $90 \%$, yaitu sebesar 99\% (2016) dan 97\% (2017). Sedangkan regulasi pelaporan corporate responsibility Malaysia sebagian masih bersifat sukarela. Hal ini juga tercermin dari regulasi yang diamandemenkan oleh Bursa Malaysia mengenai Persyaratan Pencatatan Main Market dan Persyaratan Pencatatan ACE Market terkait dengan pernyataan keberlanjutan dalam laporan tahunan pada bulan Oktober 2015. Regulasi tersebut mewajibkan emiten terdaftar di Main Market yang memiliki kapitalisasi pasar lebih dari RM 2 miliar untuk mengungkapkan Sustainability Statements dalam laporan tahunan pada atau setelah 31 Desember 2016 (Sustainable Stock Exchanges Initiative).

Profitabilitas di Indonesia mengalami peningkatan pada tahun 2017. Hal ini ditandai dengan pendapat Direktur Penilaian Perusahaan BEI Samsul Hidayat yang mengemukakan bahwa laba bersih dari 401 perusahaan yang terdaftar di BEI mengalami kenaikan sebesar 23,07\% dari Rp 603,6 triliun pada tahun 2016 menjadi Rp 742,9 triliun pada tahun 2017 (Melani, 2018). Akan tetapi, OJK mengemukakan bahwa terjadi penurunan profitabilitas antara tahun 2015 dan 2016 sebesar 0,37\% (ROA), 1,52\% (ROE) dan 5,61\% (NPM) (OJK, 2017). Solvabilitas di perusahaan perbankan Indonesia mengalami penurunan pada tahun 2016. Debt to Asset Ratio menurun sebesar $1,73 \%$ menjadi $80,59 \%$ pada tahun 2016 dari 82,32\% pada tahun 2015. Sedangkan Debt to Equity Ratio menurun sebesar $104,66 \%$ menjadi $576,39 \%$ pada tahun 2016 dari $681,05 \%$ pada tahun 2015 (OJK, 2017). Ukuran perusahaan di Indonesia mengalami peningkatan pada tahun 2017 yang ditandai dengan peningkatan total aset dari 464 perusahaan tercatat di BEI sebesar $11,11 \%$ dari $\mathrm{Rp}$ 9.057 triliun pada tahun 2016 menjadi Rp 10.064 triliun pada tahun 2017 (Melani, 2018). Peningkatan total aset juga terjadi di perusahaan perbankan yang terdaftar di BEI dari 5.191.692.277.000.000 pada tahun 2015 menjadi 5.797.722.590.000.000 pada tahun 2016 (OJK, 2017).

Profitabilitas di Malaysia selalu mengalami peningkatan sejak tahun 2006 hingga tahun 2017. Hal ini ditandai dengan kenaikan pendapatan tetap perusahaan terdaftar di Bursa Malaysia pada awal pertengahan tahun 2017 sebesar 6,8\% dari RM 1,17 triliun pada akhir tahun 2016 menjadi RM 1,25 triliun pada awal pertengahan tahun 2017. Profitabilitas di sektor perbankan menunjukkan penurunan dari tahun 2014-2015 dengan ROA sebesar 0,2\% dan ROE sebesar 2,9\%. Sedangkan pada tahun 2016, ROA tidak mengalami kenaikan dan ROE meningkat sebesar 0,2\% (World Bank, 2017). Solvabilitas di Malaysia mengalami peningkatan selama tahun 20142016 sebesar 4\% dari tahun 2014-2015 dan 0,4\% dari tahun 2015-2016 (World Bank, 2017). Ukuran perusahaan di Malaysia mengalami peningkatan yang ditandai dengan peningkatan total aset sebesar 7,3\% dari RM 696,3 miliar pada tahun 2016 menjadi RM 751 miliar pada awal pertengahan tahun 2017.

Berdasarkan uraian di atas, maka judul penelitian yang diangkat dalam penelitian ini adalah "Pengaruh Profitabilitas, Solvabilitas, dan Ukuran Perusahaan Terhadap Pengungkapan Sustainability Report pada Perusahaan Perbankan yang Terdaftar di Bursa Efek Indonesia dan Bursa Efek Malaysia Periode 2013-2017."

\subsection{Rumusan Masalah}

Permasalahan yang akan dikaji dalam penelitian ini dirumuskan sebagai berikut:

1) Apakah Profitabilitas, Solvabilitas, dan Ukuran Perusahaan berpengaruh terhadap pengungkapan Sustainability Report pada perusahaan perbankan yang terdaftar di Bursa Efek Indonesia dan Bursa Efek Malaysia periode 2013-2017 secara simultan? 
2) Apakah Profitabilitas, Solvabilitas, dan Ukuran Perusahaan berpengaruh terhadap pengungkapan Sustainability Report pada perusahaan perbankan yang terdaftar di Bursa Efek Indonesia dan Bursa Efek Malaysia periode 2013-2017 secara parsial?

3) Berapa besar pengaruh Profitabilitas, Solvabilitas, dan Ukuran Perusahaan terhadap pengungkapan Sustainability Report pada perusahaan perbankan yang terdaftar di Bursa Efek Indonesia dan Bursa Efek Malaysia periode 2013-2017?

\section{TINJAUAN PUSTAKA, KERANGKA PEMIKIRAN DAN HIPOTESIS}

\subsection{Tinjauan Pustaka}

\subsubsection{Sustainability Report}

Sustainability reporting merupakan instrumen bagi perusahaan untuk menginformasikan kinerja lingkungan, sosial, dan ekonominya kepada seluruh pemangku kepentingan (stakeholders) (Tarigan dan Semuel, 2014) dalam rangka merealisasikan tujuan pembangunan berkelanjutan sebagai wujud pertanggungjawaban perusahaan (Dilling, 2010). Tujuan pembangunan berkelanjutan dapat terealisasi apabila informasi sustainability report memenuhi karakteristik kualitas informasi. Kualitas informasi yang mendasar agar informasi tersebut bernilai dalam pengambilan keputusan yaitu relevansi (relevance) dan representasi setia (faithful representation) (SFAC 8, Chapter 3). Selain itu, kualitas informasi lainnya yang mendukung kedua kualitas informasi ini adalah komparabilitas (comparability), mampu diverifikasi (verifiability), tepat waktu (timeliness), dan mudah dimengerti (understandability) (Moore dan Poznanski, 2015).

Konsep sustainability report awalnya diperkenalkan oleh John Elkington (Aggarwal, 2013; Wijayanti, 2016; Simbolon dan Sueb, 2016; Tarigan dan Semuel, 2014) yang menyatakan bahwa terdapat tiga aspek yang berkaitan dengan sustainability report, yaitu lingkungan (planet), sosial (people), dan ekonomi (profit) yang dikenal sebagai Triple Bottom Line (Elkington, 1997). TBL ini pada awal tahun 1990an dilaporkan dalam suatu laporan tahunan (Elliott dan Elliott, 2011). Konsep TBL harus menjadi bagian dari strategi perusahaan untuk membangun keunggulan bersaing (Porter dan Kramer, 2006). Hal ini dikarenakan pengungkapan TBL mampu meningkatkan transparansi dan melihat ancaman dan risiko yang dihadapi oleh perusahaan serta peluang di masa yang akan datang (Sudana et al, 2014), sehingga perusahaan dapat menilai aset dan leverage dengan lebih akurat dan dapat memanfaatkan modalnya seefisien dan seefektif mungkin (Hammer dan Pivo, 2016).

Pengungkapan informasi suatu perusahaan dalam laporan keberlanjutan dapat berupa pengungkapan wajib (mandatory disclosure) dan pengungkapan sukarela (voluntary disclosure) (Wardani, 2012; GRI, 2012). Selain itu, pengungkapan sustainability report juga mampu berupa informasi keuangan maupun informasi non keuangan. Informasi keuangan merupakan hal yang terpenting bagi pengguna informasi keuangan namun informasi non-keuangan juga sama pentingnya (Aktas et al, 2013). Salah satu media untuk pelaporan keberlanjutan organisasi adalah laporan tahunan (Farneti dan Guthrie, 2009).

Pengungkapan informasi keberlanjutan perusahaan sebagian besar mengikuti pedoman untuk pelaporan keberlanjutan agar dapat lebih diandalkan. Pedoman pelaporan tersebut salah satunya adalah Global Reporting Initiative (GRI, 2012). Kerangka GRI merupakan kumpulan pedoman pelaporan dokumen yang dikembangkan melalui proses konsultatif multi-stakeholder global yang dirancang untuk membantu perusahaan dalam mempersiapkan laporan keberlanjutan dan pengungkapan Economic, Social, Government (ESG). Dokumen pedoman GRI direvisi secara periodik untuk memastikan bahwa dokumen tersebut dapat terus memenuhi kebutuhan masyarakat dan unit bisnis pada abad ke-21 (Ernst and young, 2013).

\subsubsection{Kinerja Keuangan}

Kinerja keuangan merupakan salah satu pedoman yang dipakai oleh manajemen untuk mengelola sumber daya-sumber daya yang telah dipercayakan (Simbolon dan Sueb, 2016; Elliott dan Elliott, 2011). Agar kinerja keuangan dapat diukur, maka diperlukan suatu analisis yang disebut sebagai analisis rasio keuangan (Kamatra dan Kartikaningdyah, 2015; Robinson et al, 2015). Analisis rasio dalam penelitian ini menggunakan analisis rasio profitabilitas dan rasio solvabilitas. Rasio profitabilitas mengacu pada kemampuan perusahaan untuk menghasilkan laba atas dana yang diinvestasikan (Rahman, 2017; Grüber, 2015). Sedangkan rasio solvabilitas mencerminkan kemampuan perusahaan dalam memenuhi seluruh kewajibannya dengan menggunakan semua aset ketika perusahaan tersebut dilikuidasi (Satryo et al, 2016).

\subsubsection{Ukuran Perusahaan}

Ukuran perusahaan mempunyai pengaruh pada perusahaan dalam hal kemampuan untuk menanggung akibat dari berbagai macam situasi yang akan dihadapi perusahaan (Andreas et al, 2015). Perusahaan-perusahaan besar umumnya memiliki sumber daya besar sehingga perusahaan perlu dan mampu membiayai informasi untuk kepentingan internal secara keseluruhan. Sebaliknya, perusahaan kecil membutuhkan biaya tambahan yang lebih besar apabila perusahaan ingin informasinya diungkapkan secara komprehensif. Jadi, dapat diasumsikan bahwa perusahaan kecil menghadapi tekanan politik yang lebih kecil dibandingkan dengan perusahaan besar (Mapparessa et al, 2017). 
2.2. Kerangka Pemikiran

\subsubsection{Hubungan antar Teori-teori yang Mendasari Sustainability Report}

Konsep sustainability report memiliki hubungan dengan teori triple bottom line karena konsep awal munculnya sustainability report berasal dari teori tersebut. Awalnya, pengungkapan sustainability report diungkapkan dalam laporan tahunan dengan tiga aspek triple bottom line, yaitu lingkungan, sosial, dan ekonomi (Elliott dan Elliott, 2011). Jadi, kesimpulannya triple bottom line merupakan unsur dalam pengungkapan sustainability report.

Informasi yang transparan umumnya akan mendapatkan kepercayaan dari berbagai pihak sebab hal ini berkaitan erat dalam menjamin kualitas informasi dalam suatu laporan. Karakteristik kualitas informasi tidak dapat terwujud dengan baik apabila tidak didukung oleh transparansi. Oleh karena itu, transparansi merupakan suatu faktor penting yang harus disadari oleh perusahaan karena hal tersebut dapat mempengaruhi tingkat kepercayaan stakeholder kepada perusahaan yang bersangkutan. Stakeholder merupakan suatu kelompok yang akan menentukan keberlanjutan dari suatu organisasi (Freeman, 1984). Upaya untuk meningkatkan transparansi supaya dipercaya oleh stakeholder dan memperoleh relasi dan legitimasi stakeholder yaitu dengan sustainability report.

Legitimasi yang didapatkan oleh perusahaan merupakan bukti pengakuan bahwa bisnis perusahaan adalah legal (Simbolon dan Sueb). Perusahaan akan mendapatkan legitimasi atas aktivitasnya dari masyarakat apabila perusahaan terus menjalankan aktivitasnya dengan berusaha menjalani norma yang terdapat dalam lingkungan sekitar ataupun masyarakat (Simbolon dan Sueb, 2016; Wardani, 2012). Kebutuhan untuk melegitimasi tindakannya mendorong perusahaan untuk membuat laporan keberlanjutan, karena pengungkapan informasi laporan keberlanjutan penting untuk mengubah persepsi masyarakat terhadap perusahaan (Andreas et al, 2015).

Proses dalam menyediakan informasi sustainability report yang berkualitas yang dilakukan oleh perusahaan dapat dipengaruhi oleh konflik internal perusahaan. konflik tersebut dapat terjadi apabila terdapat pertentangan keinginan/tujuan antara para agen (manajer) yang melaksanakan tugas dan prinsipal (pemilik) (Scott, 2015). Masalah ini dapat disebut juga sebagai masalah/konflik keagenan, yang dapat terjadi karena terdapat asimetri informasi antara manajemen dan para pemegang saham. Konflik tersebut dapat mengakibatkan informasi yang dipublikasikan dalam sustainability report tidak lengkap dan kemungkinan akan ada informasi yang dimanipulasi, sehingga hal tersebut dapat merugikan prinsipal khususnya investor. Agar dapat mengurangi asimetri informasi, dibutuhkan suatu alat pengawasan agar transparansi perusahaan dapat meningkat. Salah satu upaya perusahaan dalam meningkatkan pengawasan adalah dengan mengungkapkan sustainability report. Pengungkapan sustainability report secara meluas dapat meningkatkan pengawasan (Wardani, 2012), mengurangi asimetri informasi, menurunkan tingkat risiko dan tingkat ketidakpastian yang diterima oleh investor, mendukung pengambilan keputusan, meningkatkan efisiensi pasar, dan meningkatkan kinerja keuangan (Aggarwal, 2013).

\subsubsection{Pengaruh Profitabilitas Terhadap Pengungkapan Sustainability Report}

Profitabilitas yang tinggi akan memotivasi para manajer untuk mengungkapkan informasi yang lebih rinci agar manajer dapat memberikan keyakinan pada investor mengenai profitabilitas perusahaan (Singhvi dan Desai, 1971). Hal ini dikarenakan profit merupakan perwujudan dari hasil usaha atau kinerja dari manajer (Wardani, 2012). Jadi, dapat disimpulkan bahwa semakin rendah profitabilitas suatu perusahaan, kemungkinan perusahaan akan melakukan pengungkapan yang lebih kecil begitupula sebaliknya (Wardani, 2012). Pengungkapan sustainability report mampu meningkatkan nilai perusahaan (Saputro dkk, 2013) serta menggambarkan kinerja perusahaan yang baik sehingga dapat diterima oleh masyarakat (Lucia dan Panggabean, 2018).

\subsubsection{Pengaruh Solvabilitas Terhadap Pengungkapan Sustainability Report}

Semakin tinggi rasio solvabilitas, maka risiko finansial akan semakin besar (Robinson et al, 2015; Lucia dan Panggabean, 2018). Hal ini akan mendorong perusahaan untuk berusaha melaporkan profitabilitas yang tinggi (Saputro dkk, 2013; Lucia dan Panggabean, 2018) agar dapat meyakinkan para stakeholder-nya untuk memberikan pinjaman dan menanamkan modalnya (Saputro dkk, 2013). Perusahaan yang memiliki banyak hutang akan memiliki kemungkinan untuk mengungkapkan informasi (sustainability report) lebih luas supaya kinerjanya tetap dapat dipercaya oleh kreditor (Wardani, 2012). Namun, pandangan lain mengemukakan bahwa solvabilitas yang tinggi akan mengurangi pengungkapan sustainability report sebab hal tersebut dilakukan untuk mengurangi biayabiaya supaya dapat meningkatkan profitabilitas (Saputro dkk, 2013).

\subsubsection{Pengaruh Ukuran Perusahaan Terhadap Pengungkapan Sustainability Report}

Perusahaan besar akan berada di bawah tekanan publik untuk melakukan lebih banyak tanggung jawab sosialnya karena mendapat lebih banyak perhatian dari masyarakat (Patten, 1991; Cowen et al, 1987; Mapparessa et al, 2017). Hal ini dikarenakan perusahaan besar memiliki dampak kepada masyarakat yang lebih besar dibandingkan dengan 
perusahaan kecil. Sehingga dapat disimpulkan bahwa ukuran perusahaan berdampak positif terhadap pengungkapan sustainability report.

Berdasarkan kerangka pemikiran di atas, maka model penelitian ini adalah sebagai berikut:

Gambar 1.

Model Penelitian

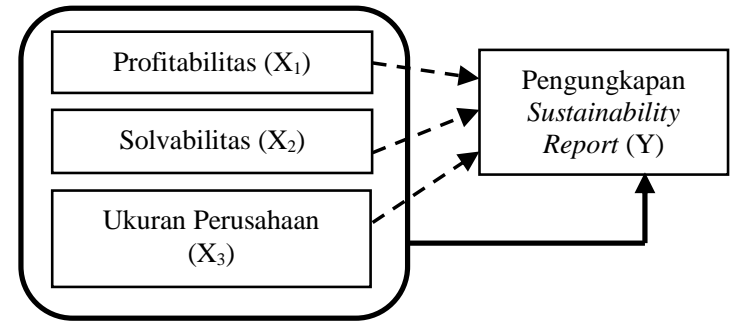

2.3. Hipotesis

$\mathrm{H}_{1}$ : Profitabilitas, Solvabilitas, dan Ukuran Perusahaan mempunyai pengaruh secara simultan terhadap pengungkapan Sustainability Report.

$\mathrm{H}_{2.1}$ : Profitabilitas mempunyai pengaruh secara parsial terhadap pengungkapan Sustainability Report.

$\mathrm{H}_{2.2}$ : Solvabilitas mempunyai pengaruh secara parsial terhadap pengungkapan Sustainability Report.

$\mathrm{H}_{2.3}$ : Ukuran Perusahaan mempunyai pengaruh secara parsial terhadap pengungkapan Sustainability Report.

\section{METODOLOGI PENELITIAN}

\subsection{Populasi dan Sampel}

Populasi penelitian ini adalah perusahaan perbankan yang terdaftar di BEI dan Bursa Malaysia tahun 2013-2017. Sampel ditarik berdasarkan purposive sampling dengan memenuhi beberapa kriteria berikut:

1) Perusahaan sampel merupakan perusahaan yang terdaftar sebagai bank domestik, bukan bank internasional.

2) Perusahaan sampel merupakan perusahaan komersial, bukan perusahaan syariah.

3) Perusahaan sampel merupakan perusahaan yang memiliki laporan keberlanjutan (sustainability report) dari tahun 2013-2017.

4) Perusahaan sampel merupakan perusahaan yang mengungkapkan laporan keberlanjutannya (sustainability report) minimal sebanyak $50 \%$ dari salah satu atau beberapa item yang tercantum dalam segi lingkungan, sosial, dan ekonomi selama tahun 2013-2017.

Berdasarkan purposive sampling, maka perusahaan yang dijadikan sampel adalah 33 perusahaan Indonesia dan 9 perusahaan Malaysia, dengan total data panel sebanyak 210 observasi yang terdiri dari 165 (Indonesia) dan 45 (Malaysia). Jika diterapkan per tahun, maka total observasinya sebanyak 167 observasi (Indonesia) dan 45 observasi (Malaysia), sehingga totalnya adalah 212 observasi.

\subsection{Variabel Penelitian}

Variabel dependen dalam penelitian ini adalah pengungkapan sustainability report, sebagaimana telah diteliti oleh beberapa peneliti lainnya (Aktas et al, 2013; Wijayanti, 2016; Simbolon dan Sueb, 2016; Tarigan dan Semuel, 2014; Wardani, 2012; Ching et al, 2014; Andreas et al, 2015; Dibia dan Onwuchekwa, 2015; Mapparessa et al, 2017; Lucia dan Panggabean, 2018; Aggarwal, 2013; Santhirasegar et al, 2018; Saputro dkk, 2013; Zainal et al, 2013). Sedangkan variabel independen dalam penelitian ini adalah profitabilitas, solvabilitas, dan ukuran perusahaan. Profitabilitas diukur dengan Return on Assets (ROA), Return on Equity (ROE), dan Net Interest Margin (NIM) sebagaimana dilakukan oleh beberapa peneliti (Wijayanti, 2016; Simbolon dan Sueb, 2016; Tarigan dan Semuel, 2014; Wardani, 2012; San dan Heng, 2013; Jamal et al, 2012; Saputro dkk, 2013; Satryo et al, 2016; Rahman, 2017; Lucia dan Panggabean, 2018; Santhirasegar et al, 2018; Aggarwal, 2013; Kamatra dan Kartikaningdyah, 2015; Mravlja, 2017; Anwar et al, 2016; Septina, 2017; An, 2016). Solvabilitas diukur dengan Debt to Assets Ratio dan Debt to Equity Ratio sebagaimana dilakukan oleh peneliti lain (Satryo et al, 2016; Rahman, 2017; Wardani, 2012; Saputro dkk, 2013; Anwar et al, 2016, Lucia dan Panggabean, 2018). Ukuran perusahaan diukur dengan logaritma natural total aset sebagaimana dilakukan oleh peneliti lainnya (Simbolon dan Sueb, 2016; Wardani, 2012; San dan Heng, 2013; Andreas et al, 2015; Dibia dan Onwuchekwa, 2015; Mapparessa et al, 2017; Lucia dan Panggabean, 2018; Mravlja, 2017).

Tabel 1.

Operasionalisasi Variabel

\begin{tabular}{|c|c|c|c|}
\hline $\begin{array}{l}\text { Vari } \\
\text { abel }\end{array}$ & Definisi & Indikator & Skala \\
\hline $\begin{array}{l}\text { Sust } \\
\text { aina } \\
\text { bility } \\
\text { Repo } \\
\text { rt } \\
\text { (Y) }\end{array}$ & $\begin{array}{l}\text { Sustainability } \\
\text { Report } \\
\text { merupakan } \\
\text { informasi yang } \\
\text { publikasikan } \\
\text { oleh perusahaan } \\
\text { yang } \\
\text { mencerminkan } \\
\text { kinerjanya } \\
\text { dalam aspek } \\
\text { lingkungan, } \\
\text { sosial, dan } \\
\text { ekonomi }\end{array}$ & $\begin{array}{l}\text { Indeks } S R \\
=\frac{\text { jumlah item } S R}{91 \text { item } S R}\end{array}$ & Rasio \\
\hline \multirow{3}{*}{$\begin{array}{l}\text { Profi } \\
\text { tabili } \\
\text { tas } \\
\left(\mathrm{X}_{1}\right)\end{array}$} & \multirow{3}{*}{$\begin{array}{l}\text { kemampuan } \\
\text { perusahaan } \\
\text { untuk } \\
\text { menghasilkan } \\
\text { laba/keuntungan } \\
\text { atas dana yang } \\
\text { diinvestasikan }\end{array}$} & $R O A=\frac{E A T}{\text { Total Aktiva }}$ & Rasio \\
\hline & & $\begin{array}{l}\text { ROE } \\
=\frac{\text { EAT }}{\text { Ekuitas Perusahaan }}\end{array}$ & Rasio \\
\hline & & $\begin{array}{l}\text { NIM } \\
=\frac{\text { Net Interest Income }}{\text { Rata }- \text { rata }} \\
\text { Aktiva Produktif }\end{array}$ & Rasio \\
\hline
\end{tabular}




\begin{tabular}{|c|c|c|c|}
\hline \multirow{2}{*}{$\begin{array}{l}\text { Solv } \\
\text { abilit } \\
\text { as } \\
\left(\mathrm{X}_{2}\right)\end{array}$} & \multirow{2}{*}{$\begin{array}{l}\text { Rasio } \\
\text { solvabilitas } \\
\text { menunjukkan } \\
\text { kemampuan } \\
\text { perusahaan } \\
\text { untuk } \\
\text { memenuhi } \\
\text { kewajibannya } \\
\text { dengan } \\
\text { menggunakan } \\
\text { seluruh aset } \\
\end{array}$} & $D A R=\frac{\text { Total Utang }}{\text { Total Aset }}$ & Rasio \\
\hline & & $D E R=\frac{\text { Total Utang }}{\text { Total Ekuitas }}$ & Rasio \\
\hline $\begin{array}{l}\text { Ukur } \\
\text { an } \\
\text { Peru } \\
\text { saha } \\
\text { an } \\
\left(\mathrm{X}_{3}\right)\end{array}$ & $\begin{array}{l}\text { Ukuran sebuah } \\
\text { perusahaan } \\
\text { tergantung pada } \\
\text { sejumlah faktor, } \\
\text { seperti } \\
\text { penerimaan } \\
\text { bruto, jumlah } \\
\text { pekerja dan } \\
\text { total aset }\end{array}$ & $\begin{array}{l}\text { Firm Size } \\
=\text { Ln Total Assets }\end{array}$ & Rasio \\
\hline
\end{tabular}

\section{HASIL DAN PEMBAHASAN}

\subsection{Hasil Penelitian}

\subsubsection{Uji Asumsi Klasik}

Jumlah observasi yang dijadikan fokus dalam penelitian ini berdasarkan rata-rata keseluruhan (Totalitas) awalnya berjumlah 165 observasi (Indonesia) dan 45 observasi (Malaysia), sedangkan berdasarkan rata-rata per tahun berjumlah 167 observasi (Indonesia) dan 45 observasi (Malaysia). Namun, setelah dilakukan uji asumsi klasik, terdapat distribusi data yang tidak normal pada data panel Indonesia (baik totalitas maupun per tahun). Oleh karena itu, peneliti mengurangi data observasi yang memiliki nilai outlier. Sehingga jumlah observasi yang diteliti adalah 129 observasi (Indonesia Totalitas) dan 136 observasi (Indonesia - Per Tahun). Data panel Malaysia (Totalitas dan Per Tahun) juga menunjukkan sebuah data outlier berdasarkan analisis statistik deskriptif. Oleh karena itu, peneliti membuang data outlier tersebut, sehingga jumlah observasi data panel Malaysia adalah 44 observasi. Jumlah observasi keseluruhan yang diuji adalah 180 observasi.

\subsubsection{Uji Normalitas}

Penelitian ini menggunakan uji Kolmogorov-Smirnov Test untuk uji normalitas. Hasil perhitungan OneSample Kolmogorov-Smirnov Test data panel Indonesia (Totalitas) menunjukkan nilai sig. lebih besar dari 0,05 yaitu 0,200 yang berarti data terdistribusi secara normal. Hasil perhitungan OneSample Kolmogorov-Smirnov Test data panel Malaysia (Totalitas dan Per Tahun) menunjukkan nilai sig. uji K-S 0,200, lebih besar dari 0,05 yang berarti data terdistribusi secara normal. Hasil perhitungan One-Sample Kolmogorov-Smirnov Test data panel Indonesia (Per Tahun) menunjukkan nilai sig. uji K-S 0,200, lebih besar dari 0,05 yang berarti data terdistribusi secara normal.

\subsubsection{Uji Multikolinearitas}

Data panel Indonesia (Totalitas dan Per Tahun) menunjukkan masalah multikolinearitas pada proksi ROA dan ROE. Oleh karena itu, peneliti memutuskan untuk mengeluarkan variabel ROE dalam pengujian multikolinearitas. Hasil uji multikolinearitas data panel Indonesia (Totalitas) menunjukkan semua variabel memiliki nilai tolerance $>0,10$ dan nilai VIF $<10$, yang berarti tidak terjadi multikolinearitas. Hasil uji multikolinearitas data panel Malaysia (Totalitas dan Per Tahun) menunjukkan semua variabel memiliki nilai tolerance $>0,10$ dan nilai VIF $<10$, yang berarti tidak terjadi multikolinearitas. Hasil uji multikolinearitas data panel Indonesia (Per Tahun) menunjukkan semua variabel memiliki nilai tolerance $>0,10$ dan nilai VIF $<10$, yang berarti tidak terjadi multikolinearitas.

\subsubsection{Uji Heteroskedastisitas}

Hasil perhitungan uji heteroskedastisitas data panel Indonesia (Totalitas) menunjukkan titik-titik menyebar secara acak baik di atas maupun di bawah angka 0 pada sumbu $\mathrm{Y}$, yang berarti tidak terjadi heteroskedastisitas (Lihat Gambar 2).

\section{Gambar 2.}

Hasil Uji Heteroskedastisitas (Scatterplot) Data Panel Indonesia (Totalitas)

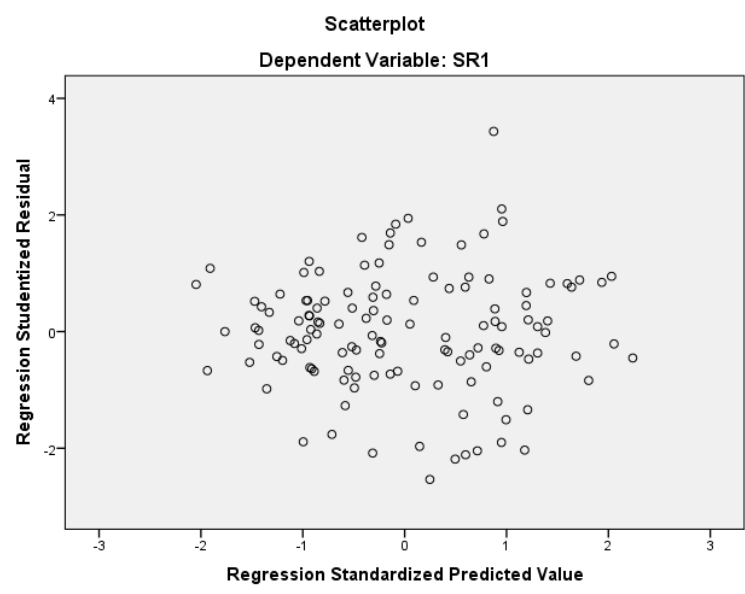

Hasil perhitungan uji heteroskedastisitas data panel Malaysia (Totalitas dan Per Tahun) menunjukkan titik-titik menyebar secara acak baik di atas maupun di bawah angka 0 pada sumbu Y, yang berarti tidak terjadi heteroskedastisitas (Lihat Gambar $3)$. 


\section{Gambar 3.}

Hasil Uji Heteroskedastisitas (Scatterplot) Data Panel Malaysia (Totalitas dan Per Tahun)

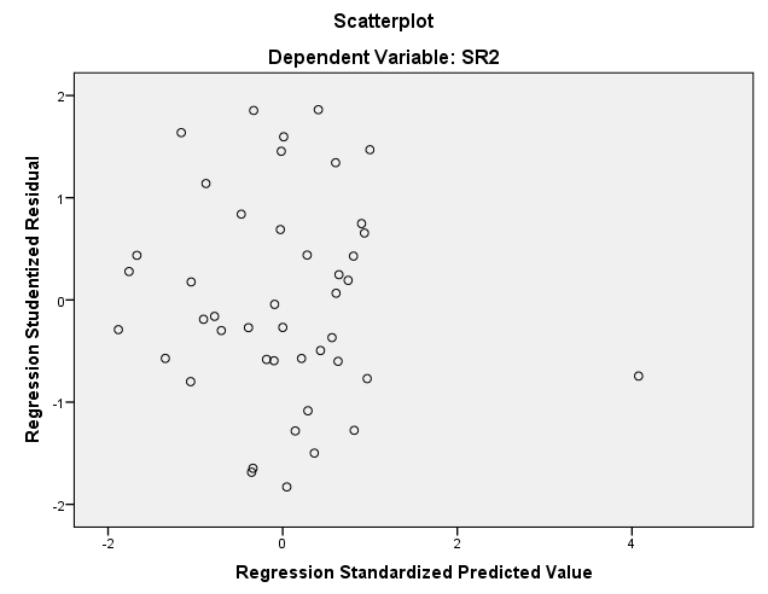

Hasil perhitungan uji heteroskedastisitas data panel Indonesia (Per Tahun) menunjukkan titik-titik menyebar secara acak baik di atas maupun di bawah angka 0 pada sumbu $\mathrm{Y}$, yang berarti tidak terjadi heteroskedastisitas (Lihat Gambar 4).

\section{Gambar 4. \\ Hasil Uji Heteroskedastisitas (Scatterplot) Data Panel Indonesia (Per Tahun)}

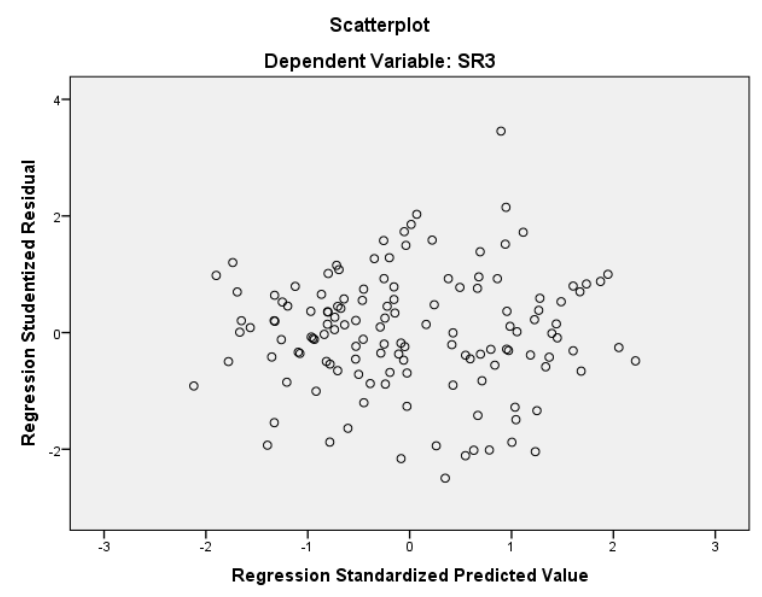

\subsubsection{Uji Autokorelasi}

Semua data panel memiliki masalah autokorelasi setelah dilakukan pengujian. Oleh karena itu, peneliti melakukan transformasi Cochrane-Orcutt untuk mengatasi masalah tersebut. Hasil uji autokorelasi data panel Indonesia (Totalitas) menunjukkan nilai DW 1,964 > du $(1,81073)$ dan kurang dari 4-du $(4-1,81073=2,18927)$, sehingga dapat disimpulkan tidak terjadi autokorelasi. Hasil uji autokorelasi data panel Malaysia (Totalitas dan Per Tahun) menunjukkan nilai DW 2,093 > du $(1,83784)$ dan kurang dari 4-du $(4-1,83784=2,16216)$, sehingga dapat disimpulkan tidak terjadi autokorelasi. Hasil uji autokorelasi data panel Indonesia (Per Tahun) menunjukkan nilai DW 1,976 > du $(1,81279)$ dan kurang dari 4-du $(4-1,81279=2,18721)$, maka dapat disimpulkan tidak terjadi autokorelasi.

\subsubsection{Pengujian Hipotesis}

\subsubsection{Uji Signifikansi Simultan (F-test)}

Uji signifikansi simultan (F-test) digunakan untuk menjawab hipotesis pertama $\left(\mathrm{H}_{1}\right)$. Nilai $\mathrm{F}$ tabel data panel keseluruhan (Indonesia dan Malaysia) adalah 2,423. Tabel 2 menunjukkan seluruh proksi dalam variabel independen yang diuji memiliki hasil yang konsisten, yaitu pengungkapan sustainability report (SR) secara simultan dipengaruhi oleh profitabilitas, solvabilitas, dan ukuran perusahaan.

\subsubsection{Uji Signifikansi Parsial (t-test)}

Uji signifikansi parsial (t-test) digunakan untuk menjawab hipotesis kedua $\left(\mathrm{H}_{2}\right)$. Nilai $\mathrm{t}$ tabel data panel keseluruhan (Indonesia dan Malaysia) adalah 1,974 .

\section{Tabel 2.}

Ringkasan Hasil Uji Signifikansi Simultan (F-test), Uji Signifikansi Parsial (t-test) dan Koefisien Determinasi Data Panel Keseluruhan (Indonesia dan Malaysia) Variabel Dependen : SR

\begin{tabular}{|c|c|c|c|c|c|c|}
\hline & Uji ke-1 & Uji ke-2 & Uji ke-3 & Uji ke-4 & Uji ke-5 & Uji ke-6 \\
\hline \multicolumn{7}{|c|}{ Sig. Parsial (t) } \\
\hline ROA &,- 965 & & &,- 643 & & \\
\hline ROE & & $-1,789$ & & & $-1,157$ & \\
\hline NIM & & &,- 893 & & &,- 619 \\
\hline DAR & $-3,951$ & $-3,805$ & $-3,919$ & & & \\
\hline DER & & & & $-2,848$ & $-2,377$ & $-2,824$ \\
\hline SIZE & 8,386 & 8,944 & 9,262 & 7,977 & 8,413 & 8,868 \\
\hline \multicolumn{7}{|c|}{ Konstanta } \\
\hline $\mathbf{H}_{2.1}$ &,- 749 &,- 191 &,- 439 &,- 507 &,- 131 &,- 312 \\
\hline $\mathbf{H}_{2.2}$ &,- 445 &,- 412 &,- 449 &,- 009 &,- 007 &,- 009 \\
\hline $\mathbf{H}_{2.3}$ &, 039 &, 042 &, 038 &, 039 &, 040 &, 038 \\
\hline \multicolumn{7}{|c|}{ Sig. Simultan } \\
\hline $\mathbf{F}$ & 64,508 & 65,906 & 64,427 & 60,249 & 60,799 & 60,231 \\
\hline Sig. &, 000 &, 000 &, 000 &, 000 &, 000 &, 000 \\
\hline \multicolumn{7}{|c|}{ Koefisien Determinasi } \\
\hline $\operatorname{Adj} \mathbf{R}^{2}$ & ,587 &, 592 &, 586 &, 570 &, 572 &, 570 \\
\hline
\end{tabular}

\section{a. Pengujian Pengaruh Profitabilitas Terhadap Pengungkapan Sustainability $\operatorname{Report}\left(\mathbf{H}_{2.1}\right)$}

Tabel 2 menunjukkan seluruh proksi dalam variabel independen yang diuji mempunyai hasil yang konsisten, yaitu pengungkapan sustainability report tidak dipengaruhi oleh profitabilitas.

b. Pengujian Pengaruh Solvabilitas Terhadap Pengungkapan Sustainability Report $\left(\mathrm{H}_{2.2}\right)$

Tabel 2 menunjukkan seluruh proksi dalam variabel independen yang diuji mempunyai hasil yang konsisten, yaitu solvabilitas berpengaruh negatif terhadap pengungkapan sustainability report. 


\section{c. Pengujian Pengaruh Ukuran Perusahaan Terhadap Pengungkapan Sustainability Report $\left(\mathbf{H}_{2.3}\right)$}

Tabel 2 menunjukkan seluruh proksi dalam variabel independen yang diuji memiliki hasil yang konsisten, yaitu ukuran perusahaan berpengaruh positif pada pengungkapan sustainability report.

\subsubsection{Uji Koefisien Determinasi}

Tabel 2 menunjukkan profitabilitas, solvabilitas, dan ukuran perusahaan mempunyai pengaruh sebesar 57\% - 59,2\% terhadap pengungkapan sustainability report.

\subsection{Pembahasan}

Hasil pengujian hipotesis pertama $\left(\mathrm{H}_{1}\right)$ data panel keseluruhan menunjukkan pengungkapan sustainability report dipengaruhi oleh profitabilitas, solvabilitas, dan ukuran perusahaan secara simultan. Hasil ini sesuai dengan teori yang menyatakan bahwa perusahaan akan meningkatkan pengungkapan sustainability report seiring dengan meningkatnya kinerja keuangan dan ukuran perusahaan. Kinerja keuangan yang baik akan memotivasi perusahaan untuk membiayai pengungkapan sustainability report melalui keuntungan yang diperolehnya dengan harapan kinerjanya dapat dipercaya oleh investor, sehingga akan berdampak pada peningkatan nilai perusahaan melalui peningkatan laba. Hasil penelitian ini konsisten dengan beberapa penelitian terdahulu (Wijayanti, 2016; Simbolon dan Sueb, 2016).

Hasil pengujian hipotesis kedua $\left(\mathrm{H}_{2.1}\right)$ data panel keseluruhan menunjukkan pengungkapan sustainability report tidak dipengaruhi oleh profitabilitas. Hasil ini tidak sesuai dengan teori yang menyatakan bahwa pengungkapan sustainability report meningkat seiring dengan peningkatan profitabilitas. Hal ini mengindikasikan bahwa perusahaan yang memiliki profitabilitas tinggi belum tentu meningkatkan pengungkapan sustainability report dikarenakan beberapa diantaranya mungkin memiliki motivasi untuk meningkatkan labanya saja. Hasil penelitian ini tidak konsisten dengan beberapa penelitian terdahulu (Wijayanti, 2016; Simbolon dan Sueb, 2016; Tarigan dan Semuel, 2014; Wardani, 2012). Namun, hasil penelitian ini konsisten dengan sebuah penelitian yang mengemukakan pengungkapan sustainability report tidak dipengaruhi oleh profitabilitas (Saputro dkk, 2013).

Hasil pengujian hipotesis kedua $\left(\mathrm{H}_{2.2}\right)$ data panel keseluruhan menunjukkan pengungkapan sustainability report dipengaruhi oleh solvabilitas secara negatif. Hasil ini sesuai dengan teori yang mengemukakan bahwa solvabilitas berdampak negatif pada pengungkapan sustainability report. Hal ini dikarenakan beberapa perusahaan memperlakukan pengungkapan sustainability report sebagai biaya, sehingga perusahaan melakukan reduksi biaya melalui pengurangan informasi sustainability report yang diungkapkan dengan harapan dapat memperbaiki profitabilitas perusahaan. Hasil penelitian ini bertentangan dengan penelitian sebelumnya (Wardani, 2012; Saputro dkk, 2013).

Hasil pengujian hipotesis kedua $\left(\mathrm{H}_{2.3}\right)$ data panel keseluruhan menunjukkan ukuran perusahaan berpengaruh positif pada pengungkapan sustainability report. Hasil ini sesuai dengan teori yang menyatakan ukuran perusahaan berdampak positif terhadap pengungkapan sustainability report. $\mathrm{Hal}$ ini mengindikasikan bahwa perusahaan yang besar cenderung akan mengungkapkan lebih banyak informasi karena memiliki dampak kepada masyarakat yang lebih besar. Hal tersebut akan mendorong perusahaan mau tak mau harus memperluas informasi yang diungkapkan dalam rangka memenuhi tuntutan masyarakat agar perusahaan tetap memperoleh legitimasi dari masyarakat. Hasil penelitian ini sejalan dengan penelitian sebelumnya yang mengemukakan pengaruh ukuran perusahaan pada pengungkapan sustainability report (Wardani, 2012; Andreas et al, 2015). Namun, hasil ini bertentangan dengan sebuah penelitian yang mengemukakan pengaruh negatif signifikan antara ukuran perusahaan dengan pengungkapan sustainability report (Mapparessa et al, 2017).

Hasil pengujian koefisien determinasi secara keseluruhan menunjukkan besarnya pengaruh yang diberikan oleh profitabilitas, solvabilitas, dan ukuran perusahaan terhadap pengungkapan sustainability report adalah $57 \%-59,2 \%$. Hal ini mengindikasikan bahwa profitabilitas, solvabilitas, dan ukuran perusahaan memberikan dampak yang cukup signifikan terhadap pengungkapan sustainability report pada perusahaan perbankan yang terdaftar di Bursa Efek Indonesia dan Bursa Efek Malaysia.

\section{SIMPULAN DAN SARAN}

\subsection{Simpulan}

1) Secara simultan, pengungkapan sustainability report dipengaruhi oleh profitabilitas, solvabilitas, dan ukuran perusahaan.

2) Secara parsial, pengungkapan sustainability report tidak dipengaruhi oleh profitabilitas. Solvabilitas berpengaruh negatif terhadap pengungkapan sustainability report. Ukuran perusahaan berpengaruh positif terhadap pengungkapan sustainability report.

3) Secara keseluruhan, pengungkapan sustainability report dipengaruhi oleh profitabilitas, solvabilitas, dan ukuran perusahaan sebesar $57 \%-59,2 \%$. 


\subsection{Saran}

1) Penelitian ini hanya berfokus pada perusahaan perbankan. Oleh karena itu, penelitian berikutnya diharapkan dapat mengambil sampel tidak hanya dari perusahaan perbankan saja, tetapi juga perusahaan sektor lainnya.

2) Penelitian berikutnya diharapkan dapat menggunakan lebih banyak variabel lain yang kemungkinan memiliki pengaruh terhadap sustainability report, seperti struktur kepemilikan saham, struktur dewan komisaris dan direksi, dan sebagainya.

3) Penelitian selanjutnya diharapkan dapat memakai lebih banyak lokasi penelitian, tidak hanya sebatas pada Indonesia dan Malaysia saja. Hal ini bertujuan untuk membantu prediksi sehingga penelitian dapat lebih valid lagi.

4) Tuntutan zaman untuk masa depan akan lebih berat lagi. Oleh karena itu, disarankan bagi perusahaan agar lebih memperhatikan dan menyadari pentingnya pengungkapan informasi sustainability report agar kinerja dan tanggung jawab sosial kepada masyarakat dapat meningkat.

\section{DAFTAR REFERENSI}

Aggarwal, P. 2013. Impact of Sustainability Performance of Company on its Financial Performance: A Study of Listed Indian Companies. Global Journal of Management and Business Research Finance Vol 13 Issue 11. pp 61-70.

Aktas, R., et al. 2013. Corporate Sustainability Reporting and Analysis of Sustainability Reports in Turkey. International Journal of Economic and Finance Vol 5 No 3. pp 113125.

An, P. H. \& Loan, V. T. K. 2016. Factors Affecting Net Interest Margin of Joint-Stock Commerical Banks in Vietnam. Journal of Economic Development 24 (1). pp 92-103.

Andreas, et al. 2015. The Effect of Firm Size, Media Exposure and Industry Sensitivity to Corporate Social Responsibility Disclosure and Its Impact on Investor Reaction. International Conference on Accounting Studies (ICAS).

Anggraeni, D. Y. \& Djakman, C. D. 2018. Pengujian Terhadap Kualitas Pengungkapan CSR di Indonesia. Ekuitas: Jurnal Ekonomi dan Keuangan Vol 2 No 1. hal 22-41.

Anwar, K., et al. 2016. Financial Ratio Analysis for Increasing the Financial Performance of the Company at Bank Bukopin. International
Journal of Sciences: Basic and Applied Research (IJSBAR) Vol 29 No 2. pp 231-236.

Blasco, J. L. \& King, A. 2017. The Road Ahead: The KPMG Survey of Corporate Responsibility Reporting 2017. KPMG International Cooperative.

Ching, H. Y., et al. 2014. Scoring Sustainability Report using GRI Indicators: A Study Based on ISE and FTSE4Good Price Indexes. Journal of Management Research Vol 6 No 3. pp 27-48.

Cowen, S. S., et al. 1987. The Impact of Corporate Characteristics on Social Responsibility Disclosure: A Typology and Frequency-Based Analysis. Accounting Organizations and Society Vol 12 No 2. pp 111-122.

Dibia, N. O. \& Onwuchekwa, J. C. 2015. Determinants of Environmental Disclosures in Nigeria: A Case Study of Oil and Gas Companies. International Journal of Finance and Accounting Vol 4 No 3. pp 145-152.

Dilling, P. F. A. 2010. Sustainability Reporting in a Global Context: What Are The Characteristics of Corporations That Provide High Quality Sustainability Reports - An Empirical Analysis. International Business and Economics Research Journal Vol 9 No 1. pp 19-30.

Elkington, J. 1997. Cannibals With Forks: The Triple Bottom Line of $21^{\text {st }}$ Century Business. Capstone Publishing Limited.

Elliott, B. \& Elliott, J. 2011. Financial Accounting and Reporting: Fourteenth Edition. Pearson Education Limited.

Ernst \& Young. 2013. Value of Sustainability Reporting: A Study by EY and Boston College Center for Corporate Citizenship.

Farneti, F. \& Guthrie, J. 2009. Sustainability Reporting by Australian Public Sector Organisation: Why they Report. Accounting Forum.

Freeman, R. E. 1984. Strategic Management: A Stakeholder Approach. Pitman Publishing Inc.

Global Reporting Initiative. 2012. Sustainability Reporting Guidelines. Version 4.

Grüber, S. 2015. Intangible Values in Financial Accounting and Reporting: An Analysis from the Perspective of Financial Analysts. Springer Gabler.

Hammer, J. \& Pivo, G. 2016. The Triple Bottom Line and Sustainable Economic Development Theory and Practice. Economic Development Quarterly. pp 1-12. 
Jamal, A. A. A., et al. 2012. Determinants of Commercial Banks Return on Asset: Panel Evidence from Malaysia. International Journal of Commerce, Business and Management (IJCBM) Vol 1 No 3. pp 55-62.

Kamatra, N. \& Kartikaningdyah, E. 2015. Effect Corporate Social Reponsibility on Financial Performance. International Journal of Economics and Financial Issues 5 (Special Issue). pp 157-164.

Lucia, L. \& Panggabean, R. R. 2018. The Effect of Firm's Characteristic and Corporate Governance to Sustainability Report Disclosure. Social Economics and Ecology International Journal (SEEIJ) Vol 2 No 1. pp 18-28.

Mapparessa, N., et al. 2017. The Effect of Political Visibility, Company Characteristics and Gender Diversity to Sustainability Report Disclosure. International Journal of Civil Engineering and Technology (IJCIET) Vol 8 Issue 9. pp 1019-1028.

Melani, A. 2018. "Laba Bersih Emiten di BEI Tumbuh 23 Persen pada 2017". Melalui https://www.liputan6.com/bisnis/read/3438713 /laba-bersih-emiten-di-bei-tumbuh-23-persenpada-2017 [26/02/2019].

Moore, W. B. \& Poznanski, P. J. 2015. Sustainability Reporting: An Accountant's Perspective. Journal of Management and Sustainability Vol 5 No 2. pp 92-96.

Mravlja, L. 2017. The Impact of Corporate Social Responsibility of Banks on Their Financial Performance. Master's Thesis. Tidak Diterbitkan. Faculty of Economics. University of Ljubljana: Slovenia.

Otoritas Jasa Keuangan. 2017. "Highlight Sektor Perbankan”. Melalui :

https://www.ojk.go.id/id/kanal/pasarmodal/Documents/Pages/Emiten-danPerusahaan-Publik/Compro\%20PPJKSektor\%20Perbankan-2017\%201.pdf [26/02/2019].

Patten, D. M. 1991. Exposure, Legitimacy, and Social Disclosure. Journal of Accounting and Public Policy Vol 10. pp 297-308.

Porter, M. E. \& Kramer, M. R. 2006. Strategy and Society: The Link Between Competitive Advantage and Corporate Social Responsibility. Harvard Business Review.

Rahman, A. A. A. A. 2017. The Relationship between Solvency Ratios and Profitability Ratios: Analytical Study in Food Industrial Companies Listed in Amman Bursa.
International Journal of Economics and Financial Issues Vol 7 No 2. pp 86-93.

Republik Indonesia. 2017. Peraturan Otoritas Jasa Keuangan Nomor 51/POJK.03/2017 tentang Penerapan Keuangan Berkelanjutan bagi Lembaga Jasa Keuangan, Emiten, dan Perusahaan Publik. Lembaran Negara Republik Indonesia Tahun 2017 Nomor 169. Sekretariat Negara. Jakarta.

Republik Indonesia. 2012. Peraturan Pemerintah Republik Indonesia Nomor 47 Tahun 2012 tentang Tanggung Jawab Sosial dan Lingkungan Perseroan Terbatas. Lembaran Negara Republik Indonesia Tahun 2012 Nomor 89. Sekretariat Negara. Jakarta.

Republik Indonesia. 1997. Undang-Undang Republik Indonesia Nomor 23 Tahun 1997 tentang Pengelolaan Lingkungan Hidup. Sekretariat Negara. Jakarta.

Republik Indonesia. 2009. Undang-Undang Republik Indonesia Nomor 32 Tahun 2009 tentang Perlindungan dan Pengelolaan Lingkungan Hidup. Lembaran Negara Republik Indonesia Tahun 2009 Nomor 140. Sekretariat Negara. Jakarta.

Republik Indonesia. 2007. Undang-Undang Republik Indonesia Nomor 40 Tahun 2007 tentang Perseroan Terbatas. Lembaran Negara Republik Indonesia Tahun 2007 Nomor 106. Sekretariat Negara. Jakarta.

Robinson, T. R., et al. 2015. International Financial Statement Analysis, $3^{\text {rd }}$ Edition. John Wiley \& Sons, Inc., Hoboken, New Jersey.

San, O. T. \& Heng, T. B. 2013. Factors Affecting the Profitability of Malaysian Commercial Banks. African Journal of Business Management Vol 7 No 8. pp 649-660.

Santhirasegar, J., et al. 2018. The Relationship Between Corporate Social Responsibility Practices and Firm Performance of Domestic Banks in Malaysia. International Journal of Engineering and Technology, 7 (2.29). pp 451456.

Saputro, D. A., dkk. 2013. Pengaruh Kinerja Keuangan Terhadap Pengungkapan Sustainability Report Perusahaan di Bursa Efek Indonesia. Accounting Analysis Journal Vol 2 No 4. hal 480-488.

Satryo, A. G., et al. 2016. The Influence of Profitability Ratio, Market Ratio, and Solvency Ratio on the Share Prices of Companies Listed on LQ 45 Index. The Indonesian Accounting Review Vol 6 No 1.pp 55-66. 
Scott, W. R. 2015. Financial Accounting Theory: Seventh Edition. Pearson Canada Inc.

Septina, F. 2017. Testing the Green Banking Model: The Effect of Performance to the Bank Index Securities Price of Srikehati. International Journal of Academic Research in Economics and Management Sciences Vol 6 No 4. pp 162171.

Simbolon, J. \& Sueb, H. M. 2016. Pengaruh Pengungkapan Sustainability Report Terhadap Kinerja Keuangan Perusahaan (Studi Empiris pada Perusahaan Tambang dan Infrastruktur Subsektor Energi yang Terdaftar di BEI Tahun 2010-2014). Simposium Nasional Akuntansi XIX Lampung.

Singhvi, S. S. \& Desai, H. B. 1971. An Empirical Analysis of the Quality of Corporate Financial Disclosure. The Accounting Review Vol $46 \mathrm{No}$ 1. pp 129-138.

Sudana, I. P., et al. 2014. A Philosophical Thought on Sustainability Accounting. Research Journal of Finance and Accounting Vol 5 No 9.

Tarigan, J. \& Semuel, H. 2014. Pengungkapan Sustainability Report dan Kinerja Keuangan. Jurnal Akuntansi dan Keuangan Vol 16 No 2. hal 88-101.

Wardani, R. P. 2012. Faktor-faktor yang Mempengaruhi Luas Pengungkapan Sukarela. Jurnal Akuntansi dan Keuangan Vol 14 No 1. hal 1-15.

Wijayanti, R. 2016. Pengaruh Pengungkapan Sustainability Report Terhadap Kinerja Keuangan Perusahaan. Syariah Paper Accounting FEB UMS. hal 39-51.

World Bank. 2017. "Malaysia Economic Monitor December 2017: Turmoil to Transformation 20 Years after the Asian Financial Crisis". Melalui :

http://documents.worldbank.org/curated/en/56 2821513004746217/pdf/122007-REVISED-

Malaysia-Economic-Monitor-2017-FA2-1WEB-Full.pdf [26/02/2019]

Zainal, D., et al. 2013. A Longitudinal Analysis of Corporate Social Responsibility Reporting (CSRR) in Malaysia Public Listed Firm: Preand Post- Mandatory CSRR Requirement. International Journal of Advanced Research in Management and Social Sciences Vol 2 No 1. pp 245-262.

http://www.capitalmarketsmalaysia.com/fixedincome/, diakses pada tanggal 26 Februari 2019. http://www.capitalmarketsmalaysia.com/assetmanagement/, diakses pada tanggal 26 Februari 2019.

http://www.sseinitiative.org/fact-sheet/bursa/, diakses pada tanggal 20 Februari 2019.

https://www.ojk.go.id/sustainablefinance/id/publikasi/riset-danstatistik/Pages/Sustainability-Report-bagiLembaga-Jasa-Keuangan-dan-Emiten.aspx diakses pada tanggal 20 Februari 2019.

https://tradingeconomics.com/malaysia/stock-market, diakses pada tanggal 23 Februari 2019. 